\title{
Outcomes after Surgery for Malignant Pancreatic Neuroendocrine Tumors
}

\author{
Omar Hama Ghalib Azeez Hawramy \\ Department of Digestive Surgery \\ Kurdistan Center for Gastroenterology and Hepatology \\ Ministry of Health \\ Sulaimani, Iraq \\ omarazeez978@gmail.com \\ Qalandar Hussein A. Kasnazani \\ Department of Digestive Surgery \\ Kurdistan Center for Gastroenterology and Hepatology \\ Ministry of Health \\ Sulaimani, Iraq \\ qalandaar@gmail.com
}

\author{
Karzan Seerwan Abdullah \\ Department of Surgery \\ College of Medicine \\ University of Sulaimani \\ Sulaimani, Iraq \\ karzan.abdullah@univsul.edu.iq
}

\author{
Dana Taib Gharib \\ Department of Gastroenterology and Hepatology \\ Kurdistan Center for Gastroenterology and Hepatology \\ Ministry of Health \\ Sulaimani, Iraq \\ danat.garib@gmail.com
}

\author{
Barham M.M. Salih \\ Department of Surgery \\ College of Medicine \\ University of Sulaimani \\ Sulaimani, Iraq \\ Barham.muhammed@univsul.edu.ic
}

Dara Ahmed Mohammed Department of Anatomy and Histology College of Medicine

University of Sulaimani Sulaimani, Iraq

Dara.marif@univsul.edu.iq
Volume 4 - Special Issue: 3rd International Conference on Health \& Medical Sciences: Insight into Advanced Medical Research (ICHMS 2019)

DOI:

10.24017/science.2019

.ICHMS.4

Received:

27 May 2019

Accepted: 28 June 2019

\section{Abstract}

The aim of the study is to declare the role of surgery in potentially curative malignant pancreatic neuroendocrine tumors, in term of prognosis, survival and complications after the surgical procedures. Does the surgery plays a significant role in the best patient's interest even in metastatic pancreatic neuroendocrine tumors? Clinical and pathological factors that changed the outcomes were also analyzed. It is retrospective, case series study. All patients who were undergoing surgery for malignant pancreatic neuroendocrine tumors from 2013 to 2018. Results show that, sixteen patients were recruited with a mean age at diagnosis of 49.31 years, (ranging from 19-80 years). There were 8 male and 8 female patients. Common symptoms were abdominal pain 12 (75\%) of them three cases had clinical jaundice 3 (18.8\%) and one case had acute pancreatitis and pancreatic necrosis. One (6.3\%) patient had functional tumor, and the rest 15 (93.8\%) were nonfunctional tumors; all of the patients were sporadic pancreatic neuroendocrine tumors. Overall morbidity was $(43.8 \%)$ with no perioperative mortality. The median follow-up period was 23 months, ranging from 5-68 months. Recurrence occurred in four cases with a median disease-free interval of 9.5 moths with grade of differentiation (P-value 0.027), lymph node metastases (P-value 0.027) and tumor stage (P-value 0.017$)$ were associated with recurrent disease. The overall 5 year survival was $81.2 \%$ and the disease free survival was $(75 \%)$ at 5 year, with grade of tumor $(P$ value 0.001), lymph node metastases (P-value 0.001), 
invasion of other visceral organs(P-value 0.018) and recurrence (P-value 0.001)were associated with decreased survival. In conclusion, pancreatic neuroendocrine tumors have favorable long-term survival after surgical resections even in the presence of liver metastases depending on the grade of differentiation of tumor and lymph node metastases rather than liver metastases and other factors.

Keywords: Pancreatic, Malignant neuroendocrine tumors, Outcomes, Survival, Recurrence.

\section{INTRODUCTION}

Neuroendocrine tumors (NETs) are a group of diseases, which include tumors arising from endocrine cells with varying prognosis. The most common primary site of NETs is the gastrointestinal tract (58\%), followed by the lungs (15\%) [1]. In fact pancreatic neuroendocrine tumors (PNETs) make up about $7 \%$ of all NETs and $8.7 \%$ of gut NETs [2]. Pancreatic neuroendocrine tumors originate from pancreatic islet cells, they are rare and special entity of pancreatic tumors and can be classified either as functional or non-functional [3-5], but the nonfunctional variety are the predominant, with symptoms arising from mass effect or due to distant metastases [6]. In metastatic PNETs,liver is the mostsignificantfor metastatic disease andlymph node involvement is observed in most of the times [7-9].

Pancreatic neuroendocrine tumors are making up to $4 \%$ of all the pancreatic malignancies [10], they are known to have a significant long-term survival when they are compared to exocrine tumors of the pancreas [11]. Despite the rarity of the PNETs, the incidence has been greatly increasing more than twice as much in the last 20-30 years [12], the rise in the incidence is greatly due to increase physicians' knowledge and advances in the diagnostic imaging [13]. Because of low morbidity and mortality, surgery is the standard treatment strategy for local PNETs [14]. Advanced technical improvement and successful resection make a great achievement in lowering overall mortality to less than $5 \%$ for resection of hepatic metastatic PNETs $[15,16]$.

In most of the times PNETs are sporadic, while 10-30\% of these tumors are part of hereditary syndromes, including Multiple Endocrine Neoplasia type I (MENI), type IV neurofibromatosis, Von Hippel - Lindau disease (VHL) and tuberous sclerosis [5].

\section{METHODS AND MATERIALS}

Patients who underwent surgery for malignant pancreatic NETs from January 2013 to December 2018 in Al-Sulaimaneyah city in north of Iraq, were recruited in a retrospective review of medical, radiological, surgical and pathological reports. Among sixteen patients, only one patient was diagnosed with functional PNET with clinical symptoms of hypoglycemia with further confirmation by measurement of blood glucose, insulin and C peptide level. The rest of the patients were being nonfunctional. Preoperative serum chromogranin A had not been done for any of the patients as somatostatin receptor scintigraphy. Preoperative radiological assessment, including contrast-enhanced computed tomography (CECT) of the abdomen, pelvis and chest, endoscopic ultrasound (EUS) with or without fine needle aspiration (FNA) had been done, preoperatively for majority of the patients.

All the patients, after assessment of both their general condition, in the physical fitness of view and tumor assessment were underwent surgery with curative intent inform of pancreaticoduodenectomy, distal pancreatectomy with splenectomy and spleen preserving distal pancreatectomy, with resection of liver metastases either synchronously or as staged operation.

All patients were examined at a regular interval by the surgical team and oncologist at outpatient clinic every three months for the first and second year and every six months later on. During the follow-up period, abdominal ultrasound every three months with six month interval 
contrast enhanced computed tomography of abdomen, pelvis and chest had been done for every patient to monitor local and distant recurrence.

Data was collected and coded. The collected data was reviewed and analyzed using the Statistical Package for Social Sciences (SPSS version 22). Descriptive statistics such as frequency and percentage was calculated. Measures of central tendency and dispersion around the mean were used to describe continuous variables. $\mathrm{P}$ value was obtained for the continuous variable usingchi-squareand was considered significant if it was less than (0.05).

Survival analysis: it was used to test the effect of some patient's predictors on the mortality and recurrence rate considering time factor until one or more of the events happened. Univariate survival function was examined using Kaplan Mayer curves with log rank test of significance to compare survival rates, then multiple stepwise Cox regression analysis was done to identify the most important factors contributed to event occurrence (mortality / remission).

Study ethic consideration, this is a retrospective study informed consent was obtained from every patient for all procedures including operative procedures, invasive diagnostic procedures and radiologic imaging.

\section{RESULTS}

A total ofsixteen patientsunderwent potentially curative surgery for neuroendocrine tumors in the pancreasfrom January 2013 to December 2018. There were 8 (50\%) men and 8 (50\%) women as shown in (table 1). The patients' mean age at diagnosis was 49.31 year (range: 19-80 years). Abdominal pain was the most frequent presenting symptom (75\%) followed by each of jaundice and back pain (18.8\%). Fifteen 15 (93.8\%) patients had nonfunctional PNETs while 1 (6.3\%) patient had functional insulinoma, all patients were sporadic, as shown in the table (1).

Table 1: Demographic and basiccharacteristics of the patients.

\begin{tabular}{|c|c|c|c|}
\hline \multicolumn{2}{|c|}{ Variables } & Frequency & Percent \\
\hline \multirow{3}{*}{ Gender } & Male & 8 & $50 \%$ \\
\cline { 2 - 4 } & Female & 8 & $50 \%$ \\
\hline \multirow{3}{*}{ Social History } & Smoker & 5 & $31.3 \%$ \\
\cline { 2 - 4 } & Alcoholic & 2 & $12.5 \%$ \\
\hline \multirow{3}{*}{ Co-morbidity } & 2 & $12.5 \%$ \\
\hline \multirow{3}{*}{ Symptoms } & Abdominal pain & 12 & $75 \%$ \\
\cline { 2 - 4 } & Back pain & 3 & $18.8 \%$ \\
\cline { 2 - 4 } & Weight loss & 0 & $0 \%$ \\
\cline { 2 - 4 } & Jaundice & 3 & $18.8 \%$ \\
\cline { 2 - 4 } & Anemia & 0 & $0 \%$ \\
\hline \multirow{3}{*}{ Disease } & Sporadic & 16 & $100 \%$ \\
\cline { 2 - 4 } & Incidental & 1 & $6.3 \%$ \\
\cline { 2 - 4 } & Functional & 1 & $6.3 \%$ \\
\hline
\end{tabular}

The tumor was located in the head of pancreas in 6 (37.5\%) patients, in the body of pancreas in 7 (43.8\%) patients, in the tail in $1(6.3 \%)$ and in $2(12.5 \%)$ patients located in the body and tail of pancreas. The average tumor size was $4 \mathrm{~cm}$ (range: $1-9 \mathrm{~cm}$ ), in one of the patients the size cannot be assessed because of necrotizing pancreatitis. Two patients had hepatic metastases on presentation, ten patients (62.6\%) were stage II and four patients (25\%) were stage IV. There were 9 (56.3\%) well differentiated G1 tumors and 3 (18.8\%) were moderately differentiated G2 tumors and four $(n=4,25 \%)$ were poorly differentiated G3 tumors. Gross invasion but without microscopic invasion of peripancreatic region including mesentery, left kidney and left adrenal 
gland) was found in three patients (18.8\%). Four of the patients (25\%) had lymph node metastases (Table 2).

Table 2: Frequency of tumor location, tumor size, metastatic status, Tumor Stages and Tumor grades.

\begin{tabular}{|c|c|c|c|}
\hline \multicolumn{2}{|l|}{ Variables } & Frequency & Percent \\
\hline \multirow{4}{*}{ Tumor location } & Head & 6 & $37.5 \%$ \\
\hline & Body & 7 & $43.8 \%$ \\
\hline & Body and tail & 2 & $12.5 \%$ \\
\hline & Tail only & 1 & $6.3 \%$ \\
\hline \multirow{4}{*}{ Tumor size } & $\mathrm{T} 1$ & 1 & $6.3 \%$ \\
\hline & $\mathrm{T} 2$ & 9 & $56.3 \%$ \\
\hline & T3 & 4 & $25 \%$ \\
\hline & $\mathrm{T} 4$ & 2 & $12.5 \%$ \\
\hline \multirow{2}{*}{ Metastases } & Liver & 2 & $12.5 \%$ \\
\hline & Peritoneal & 0 & $0 \%$ \\
\hline \multirow{6}{*}{ Tumor Stages } & $\mathrm{I}$ & 1 & $6.3 \%$ \\
\hline & IIA & 7 & $43.8 \%$ \\
\hline & IIB & 3 & $18.8 \%$ \\
\hline & IIIA & 0 & $0 \%$ \\
\hline & IIIB & 1 & $6.3 \%$ \\
\hline & IV & 4 & $25 \%$ \\
\hline \multirow{5}{*}{ Tumor Grades } & G1 & 9 & $56.3 \%$ \\
\hline & G2 & 3 & $18.8 \%$ \\
\hline & G3 & 4 & $25 \%$ \\
\hline & Lymph node metastases & 4 & $25 \%$ \\
\hline & $\begin{array}{l}\text { Invasion of other visceral } \\
\text { organs }\end{array}$ & 3 & $18.8 \%$ \\
\hline
\end{tabular}

Pancreaticoduodenectomy was carried out in 6 (37\%) patients of whom one patient had undergone synchronous hepatic metaststectomy. Distal pancreatectomy with splenectomy was carried out for 7 (43.8\%) patients, staged hepatic metastatectomy had been done for one of the patients and spleen preserving distal pancreatectomy was performed for 2 (12.5\%) patients. One of the patients (6.3\%) underwent necrosectomy for necrotizing pancreatitis (Fig.1).There was no operative mortality but (43.7\%) overall morbidity was recorded. Surgical site infection was being the most common postoperative event happened in 4 (25\%) patients followed by postoperative diabetes in $3(18.8 \%)$ patients. One patient $(6.5 \%)$ developed bile leak and one patient (6.5\%) developed pancreatic leak both of them were treated with conservative measures and they were stopped spontaneously, the type of operative procedure which had been performed was not a matter for the development of postoperative event (P-value 0.395), one patient was complaining from postoperative intra-abdominal collection for which ultrasound guided percutaneous drainage had been done (Figure.1 and 2 and Table 3 and 4). Reoperation had been done in one patient (6.5\%) for postoperative bleeding (Table 5). 
Table 3: Frequency of operative procedures and post-operative events (complications)

\begin{tabular}{|c|c|c|c|}
\hline \multicolumn{2}{|r|}{ Variables } & Frequency & Percent \\
\hline \multirow{4}{*}{ Operative procedures } & Pancreatoduodenectomy & 6 & $37.5 \%$ \\
\hline & $\begin{array}{l}\text { Spleen Preserving distal } \\
\text { Pancreatectomy }\end{array}$ & 2 & $12.5 \%$ \\
\hline & Distal pancreatectomy with splenectomy & 7 & $43.8 \%$ \\
\hline & Pancreatic necrosectomy & 1 & $6.3 \%$ \\
\hline \multirow{6}{*}{$\begin{array}{l}\text { post-operative events } \\
\text { (complications) }\end{array}$} & SSI only & 2 & $12.5 \%$ \\
\hline & $\begin{array}{l}\text { SSI + Wound dehiscence + bleeding + Pancreatic } \\
\text { leak }\end{array}$ & 1 & $6.3 \%$ \\
\hline & SSI + bile leak & 1 & $6.3 \%$ \\
\hline & Post-operative diabetes only & 2 & $12.5 \%$ \\
\hline & $\begin{array}{l}\text { Intra-abdominal collection + Post-operative } \\
\text { diabetes }\end{array}$ & 1 & $6.3 \%$ \\
\hline & No complication & 9 & $56.3 \%$ \\
\hline
\end{tabular}

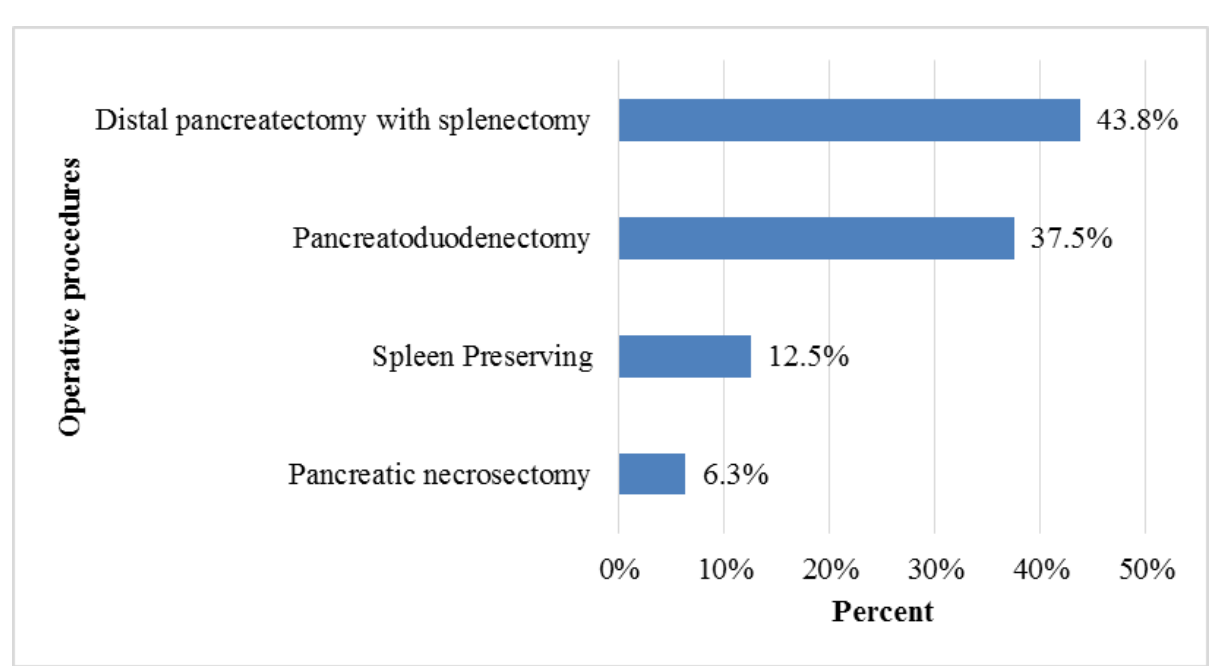

Figure 1: Frequency of operative procedure.

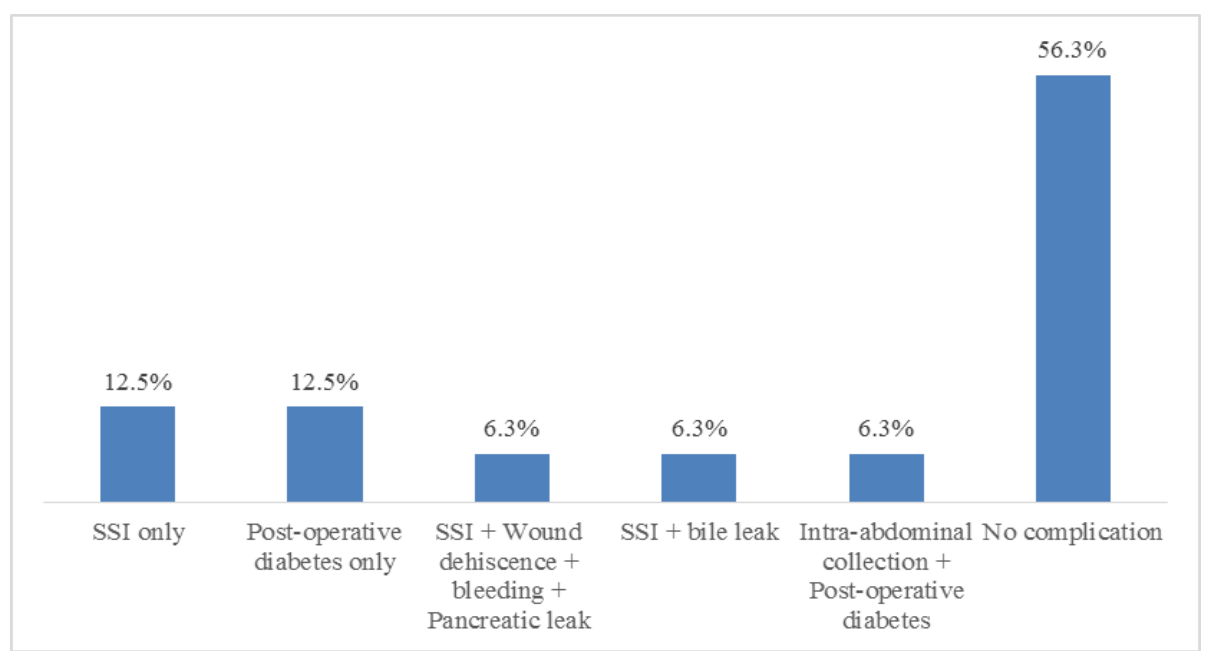

Figure 2: Frequency of post-operative events (complications). 
Table 4: Relation between operative procedures and post-operative events (complications)

\begin{tabular}{|c|c|c|c|c|c|}
\hline \multirow[b]{2}{*}{$\begin{array}{l}\text { post-operative events } \\
\text { (complications) }\end{array}$} & \multicolumn{4}{|c|}{ operative procedures } & \multirow[b]{2}{*}{$P$ value } \\
\hline & $\begin{array}{c}\text { Pancreato- } \\
\text { duodenectomy }\end{array}$ & $\begin{array}{c}\text { Spleen } \\
\text { Preserving }\end{array}$ & $\begin{array}{c}\text { Distal } \\
\text { pancreatectomy } \\
\text { with splenectomy }\end{array}$ & $\begin{array}{c}\text { Pancreatic } \\
\text { necrosectomy }\end{array}$ & \\
\hline SSI only & $1(6.3 \%)$ & $0(0 \%)$ & $0(0 \%)$ & $1(6.3 \%)$ & \multirow{6}{*}{0.395} \\
\hline $\begin{array}{c}\text { SSI + Wound } \\
\text { dehiscence + bleeding + } \\
\text { Pancreatic leak } \\
\end{array}$ & $1(6.3 \%)$ & $0(0 \%)$ & $0(0 \%)$ & $0(0 \%)$ & \\
\hline SSI + bile leak & $1(6.3 \%)$ & $0(0 \%)$ & $0(0 \%)$ & $0(0 \%)$ & \\
\hline $\begin{array}{c}\text { Post-operative diabetes } \\
\text { only }\end{array}$ & $0(0 \%)$ & $0(0 \%)$ & $2(12.5 \%)$ & $0(0 \%)$ & \\
\hline $\begin{array}{c}\text { Intra-abdominal } \\
\text { collection + Post- } \\
\text { operative diabetes } \\
\end{array}$ & $0(0 \%)$ & $0(0 \%)$ & $1(6.3 \%)$ & $0(0 \%)$ & \\
\hline No complication & $3(18.8 \%)$ & $2(12.5 \%)$ & $4(25 \%)$ & $0(0 \%)$ & \\
\hline
\end{tabular}

Recurrence had occurred in four 25\%; with a median disease free interval of 9.5 months, two of them in the liver and in the other two, the recurrence was local (Table 5).

Table 5: Follow-up and outcome of patients.

\begin{tabular}{|c|c|c|c|}
\hline \multicolumn{2}{|c|}{ Variables } & Frequency & Percent \\
\hline \multicolumn{2}{|c|}{ Re-operation } & 1 & $6.3 \%$ \\
\hline \multicolumn{2}{|c|}{ Re-admission for delayed complications } & 2 & $12.5 \%$ \\
\hline \multicolumn{2}{|c|}{ Recurrent } & 4 & $25 \%$ \\
\hline \multirow{2}{*}{ Survival } & Alive & 13 & $81.2 \%$ \\
\hline & Dead & 3 & $18.8 \%$ \\
\hline
\end{tabular}

One of the liver recurrences occurred 12 months afterresection of the primary tumor withpoorly differentiated G3 (mitosis more than 30/HPF and Ki67 50\%) and the second patient developed liver recurrence 61 months after primary tumor resection of a well differentiated G1 tumor(mitosis of 1/HPF and Ki67 of 2\%). Two patients 2 (12.5\%) developed local recurrence during follow up, one of them 7 months after primary tumor resection of a poorly differentiated G3 tumor( mitosis 10/HPF and Ki670f 60\%). The second local recurrence was being 6 months from the resection of the poorly differentiated G3 tumor with (mitosis 8/HPF and Ki67 of 40\%), with a (P-value 0.027). Neither patient with local and liver recurrences had involved margins. Both the patient and the tumor variables were identified that have significant prognostic value on tumor recurrence including cigarette smoking (P-value 0.029), high grade $\mathrm{G} 3$ tumors (Pvalue 0.027 ), lymph node involvement (P-value 0.027$)$ and the tumor stage IV (P-value 0.017$)$ Neither tumor size (P-value 0.770$)$, tumor location (P-value 0.330$)$, age of the patient (P-value 0.6 ) , the sex of the patient (P-value 0.285), angio-invasion (P-value 0.074), invasion of other visceral organs (P-value 0.064) nor the type of operative procedure (P-value 0.149) has significant impact on the recurrence (Table $6 \mathrm{~A}$ and $\mathrm{B}$ ). The mean duration of hospital stay was $(7.38 \pm 4.71)$ days. 
Table 6 (A): Correlation between recurrences with study variables

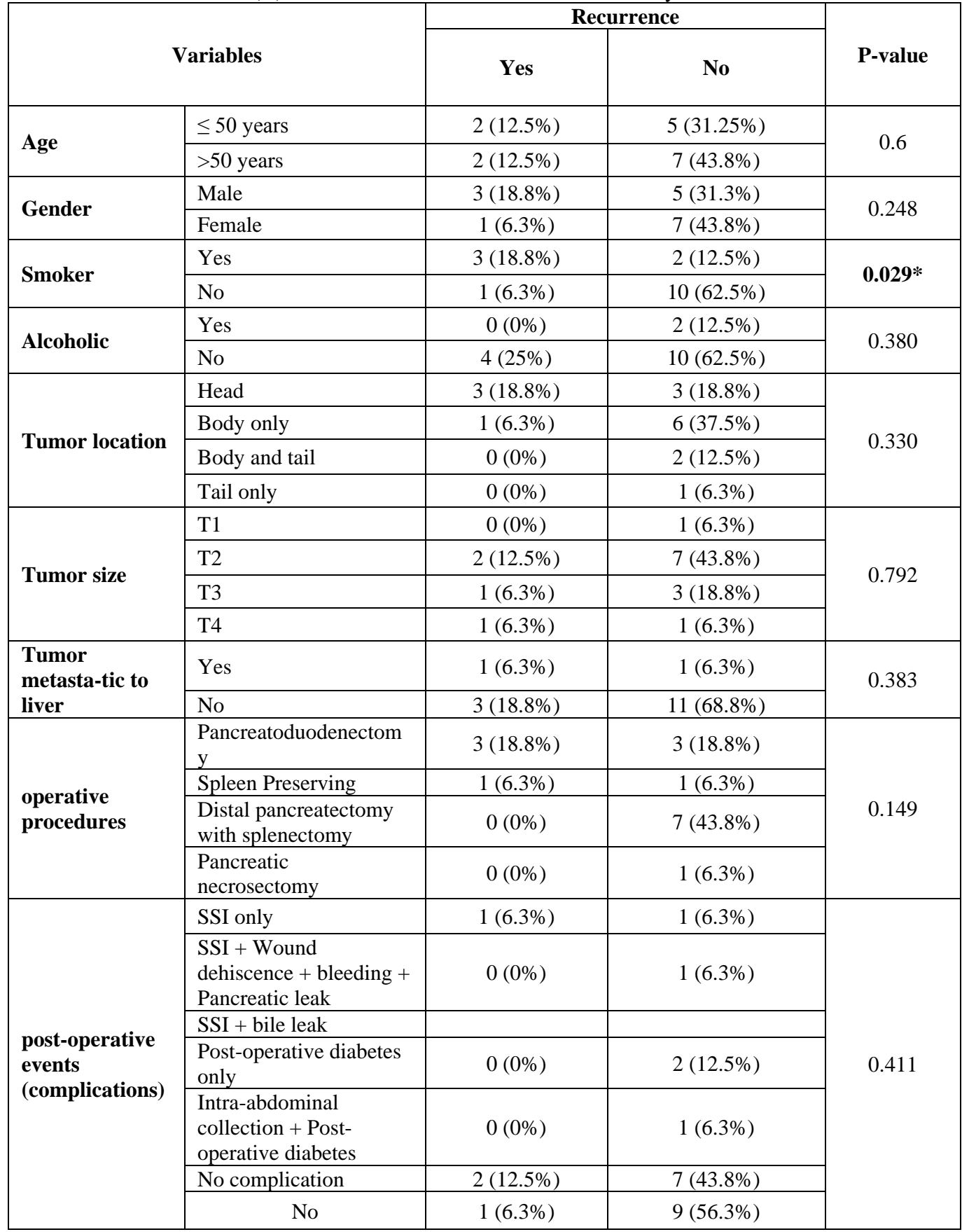


Table 6 (B): Correlation between recurrences with study variables

\begin{tabular}{|c|c|c|c|c|}
\hline \multirow{2}{*}{\multicolumn{2}{|c|}{ Variables }} & \multicolumn{2}{|c|}{ Recurrence } & \multirow[b]{2}{*}{$P$ value } \\
\hline & & Yes & No & \\
\hline \multirow{2}{*}{ Re-operation } & Yes & $0(0 \%)$ & $1(6.3 \%)$ & \multirow{2}{*}{0.551} \\
\hline & No & $4(25 \%)$ & 11 (68.8\%) & \\
\hline \multirow{2}{*}{$\begin{array}{l}\text { Re-admission for } \\
\text { delayed complications }\end{array}$} & Yes & $0(0 \%)$ & $2(12.5 \%)$ & \multirow{2}{*}{0.383} \\
\hline & No & $4(25 \%)$ & $10(62.5 \%)$ & \\
\hline \multirow{3}{*}{ Tumor Grade } & G1 & $1(6.3 \%)$ & $8(50 \%)$ & \multirow{3}{*}{$0.027 *$} \\
\hline & G2 & $0(0 \%)$ & $3(18.8 \%)$ & \\
\hline & G3 & $3(18.8 \%)$ & $1(6.3 \%)$ & \\
\hline \multirow{2}{*}{ Lymph node metastasis } & Yes & $3(18.8 \%)$ & $1(6.3 \%)$ & \multirow{2}{*}{$0.027 *$} \\
\hline & No & $1(6.3 \%)$ & $11(68.8 \%)$ & \\
\hline \multirow{2}{*}{$\begin{array}{l}\text { Invasion of other } \\
\text { visceral organs }\end{array}$} & Yes & $2(12.5 \%)$ & $1(6.3 \%)$ & \multirow{2}{*}{0.064} \\
\hline & No & $2(12.5 \%)$ & $11(68.8 \%)$ & \\
\hline \multirow{2}{*}{ Survival } & Alive & $1(6.3 \%)$ & $12(75 \%)$ & \multirow{2}{*}{$0.001 *$} \\
\hline & Dead & 3 (18.8\%) & $0(0 \%)$ & \\
\hline \multirow{2}{*}{ Receive Chemotherapy } & Yes & $3(18.8 \%)$ & $3(18.8 \%)$ & \multirow{2}{*}{0.074} \\
\hline & No & $1(6.3 \%)$ & $9(56.3 \%)$ & \\
\hline \multirow{6}{*}{ Tumor Stages } & I & $0(0 \%)$ & $1(6.3 \%)$ & \multirow{6}{*}{$0.017 *$} \\
\hline & IIA & $0(0 \%)$ & $8(43.8 \%)$ & \\
\hline & IIB & $0(0 \%)$ & $3(18.8 \%)$ & \\
\hline & IIIA & $0(0 \%)$ & $0(0 \%)$ & \\
\hline & IIIB & $1(6.3 \%)$ & $0(0 \%)$ & \\
\hline & IV & $3(18.8 \%)$ & $1(6.3 \%)$ & \\
\hline \multirow{2}{*}{ Angioinvasion } & Yes & $3(18.8 \%)$ & $3(18.8 \%)$ & \multirow{2}{*}{0.074} \\
\hline & No & $1(6.3 \%)$ & 9 (56.3\%) & \\
\hline
\end{tabular}

The median follow up period was 23 months (range: 5-68 months) as shown in the (Table 7). The five year overall survival and disease free survival were (81.2\%) and (75\%) respectively. Thirteen patient 13 (81\%)were still alive at the time ofdata analysis ,three patients died of tumor progression and recurrence despite receiving adjuvant chemotherapy, two of them died from local recurrence developed 6 and 7 months after R0 resection of the primary tumor with PT2N1M1hep.,mitosis 8/HPF , Ki67 of 40\% and PT4NM0,mitosis 10/HPF,Ki67of 60\%.The third patient developed liverrecurrence 12 months after R0 resection and died 18months after theprimary resection with (PT3N1M0, mitosis 40/HPF and Ki67 50\%), despite resection of recurrent hepatic lesion (Figure 3). 
Table 7: Survival and recurrence during the follow a period

\begin{tabular}{|c|c|c|c|}
\hline NO & Survival/months & Recurrence & Dead \\
\hline 1 & 26 & & \\
\hline 2 & 18 & 61 & 1 \\
\hline 3 & 68 & 7 & 1 \\
\hline 4 & 13 & & \\
\hline 5 & 14 & & \\
\hline 6 & 10 & & \\
\hline 7 & 10 & & \\
\hline 8 & 24 & & \\
\hline 9 & 26 & & \\
\hline 10 & 15 & & \\
\hline 11 & 8 & & \\
\hline 12 & 5 & & \\
\hline 13 & 16 & & \\
\hline 14 & 53 & & \\
\hline 15 & 54 & & \\
\hline 16 & 8 & & \\
\hline
\end{tabular}

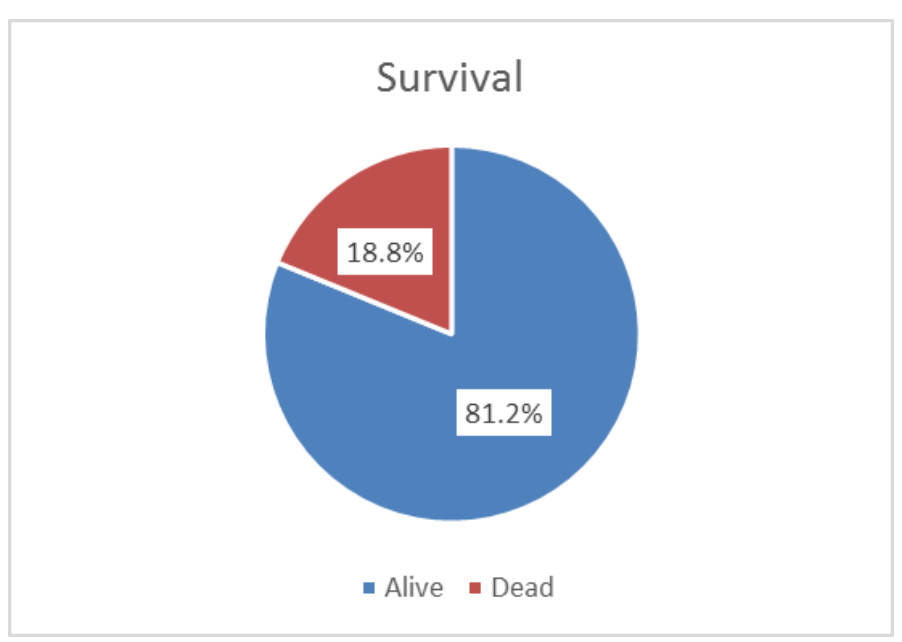

Figure 3: Outlines the five years survival.

Prognostic factors influencing survival were evaluated, highly significant factors recognized were tumor grade G3 (P-value 0.001), lymph node involvement (P-value 0.001) and tumor recurrence (P-value 0.001).With jaundice on presentation and invasion of other viscera showed significant impact on survival with (P-value 0.018). Neither the tumor size (P-value 0.581), the tumor stage (P-value 0.051), liver metastases ( $\mathrm{P}$-value 0.226$)$, the age of the patient (P-value 0.37 ) nor the sex of the patient (P-value 0.522 )were found to be significant prognostic factorson survival (Table 8, Figure 4 -A and 4 -B). 
Table 8: Correlation between survival and outcome of surgery with study variables

\begin{tabular}{|c|c|c|c|c|}
\hline \multirow{2}{*}{\multicolumn{2}{|c|}{ Variables }} & \multicolumn{2}{|c|}{ Survival } & \multirow{4}{*}{$\begin{array}{r}\text { P value } \\
0.37\end{array}$} \\
\hline & & \multirow{3}{*}{$\begin{array}{c}\text { Alive } \\
5(31.25 \%) \\
8(50.0 \%) \\
\end{array}$} & \multirow{3}{*}{$\begin{array}{c}\text { Dead } \\
2(12.5 \%) \\
1(6.25 \%) \\
\end{array}$} & \\
\hline Aro & $\leq 50$ years & & & \\
\hline Age & $>50$ years & & & \\
\hline \multirow{2}{*}{ Gender } & Male & $7(43.8 \%)$ & $1(6.3 \%)$ & \multirow{2}{*}{0.522} \\
\hline & Female & $6(37.5 \%)$ & $2(12.5 \%)$ & \\
\hline \multirow{2}{*}{ Smoker } & Yes & 3 (18.8\%) & $2(12.5 \%)$ & \multirow{2}{*}{0.142} \\
\hline & No & $10(62.5 \%)$ & $1(6.3 \%)$ & \\
\hline \multirow{2}{*}{ Alcoholic } & Yes & $2(12.5 \%)$ & $0(0 \%)$ & \multirow{2}{*}{0.468} \\
\hline & No & $11(68.8 \%)$ & $3(18.8 \%)$ & \\
\hline \multirow{3}{*}{ Symptoms } & $\begin{array}{l}\text { Abdominal } \\
\text { pain }\end{array}$ & $9(56.3 \%)$ & 3 (18.8\%) & 0.267 \\
\hline & Back pain & $2(12.5 \%)$ & $1(6.3 \%)$ & 0.473 \\
\hline & Jaundice & $1(6.3 \%)$ & $2(12.5 \%)$ & 0.018* \\
\hline \multirow{3}{*}{ Tumor location } & Head & 2 (12.5\%) & $1(6.3 \%)$ & \multirow{3}{*}{0.571} \\
\hline & Body & $8(50 \%)$ & $2(12.5 \%)$ & \\
\hline & Body and tail & 3 (18.8\%) & $0(0 \%)$ & \\
\hline \multirow{4}{*}{ Tumor size } & $\mathrm{T} 1$ & $1(6.3 \%)$ & $0(0 \%)$ & \multirow{4}{*}{0.581} \\
\hline & $\mathrm{T} 2$ & $8(50 \%)$ & $1(6.3 \%)$ & \\
\hline & T3 & $3(18.8 \%)$ & $1(6.3 \%)$ & \\
\hline & $\mathrm{T} 4$ & $1(6.3 \%)$ & $1(6.3 \%)$ & \\
\hline \multirow{2}{*}{ Re-operation } & Yes & $1(6.3 \%)$ & $0(0 \%)$ & \multirow{2}{*}{0.620} \\
\hline & No & 12 (75\%) & $3(18.8 \%)$ & \\
\hline \multirow{2}{*}{$\begin{array}{l}\text { Re-admission for } \\
\text { delayed } \\
\text { complications }\end{array}$} & Yes & 2 (12.5\%) & $0(0 \%)$ & \multirow{2}{*}{0.468} \\
\hline & No & $11(68.8 \%)$ & $3(18.8 \%)$ & \\
\hline \multirow{2}{*}{ Tumor G3 } & Yes & $1(6.3 \%)$ & $3(18.8 \%)$ & \multirow{2}{*}{ 0.001* } \\
\hline & No & $12(75 \%)$ & $0(0 \%)$ & \\
\hline \multirow{2}{*}{$\begin{array}{l}\text { Lymph node } \\
\text { metastases }\end{array}$} & Yes & $1(6.3 \%)$ & $3(18.8 \%)$ & \multirow{2}{*}{ 0.001* } \\
\hline & No & $12(75 \%)$ & $0(0 \%)$ & \\
\hline \multirow{2}{*}{$\begin{array}{l}\text { Invasion of other } \\
\text { visceral organs }\end{array}$} & Yes & $1(6.3 \%)$ & $2(12.5 \%)$ & \multirow{2}{*}{ 0.018* } \\
\hline & No & 12 (75\%) & $1(6.3 \%)$ & \\
\hline Recurrent & Yes & $1(6.3 \%)$ & $3(18.8 \%)$ & $0001 *$ \\
\hline Recurrent & No & $12(75 \%)$ & $0(0 \%)$ & $0.001^{*}$ \\
\hline & $\mathrm{I}$ & $1(6.3 \%)$ & $0(0 \%)$ & \\
\hline & IIA & $7(43.8 \%)$ & $0(0 \%)$ & \\
\hline & IIB & $3(18.8 \%)$ & $0(0 \%)$ & \\
\hline Tumor Stages & IIIA & $0(0 \%)$ & $0(0 \%)$ & 0.051 \\
\hline & IIIB & $0(0 \%)$ & $1(6.3 \%)$ & \\
\hline & IV & $2(12.5 \%)$ & $2(12.5 \%)$ & \\
\hline Tumor metastases & Yes & $1(6.3 \%)$ & $1(6.3 \%)$ & 0226 \\
\hline to liver & No & $12(75 \%)$ & $2(12.5 \%)$ & 0.220 \\
\hline Angininyasi-on & Yes & $3(18.8 \%)$ & $3(18.8 \%)$ & $0.013 *$ \\
\hline 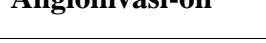 & No & $10(62.5 \%)$ & $0(0 \%)$ & \\
\hline
\end{tabular}


There was not a significant value of duration of hospital stay on the recurrence (P-value 0.074). There was an association between duration of hospital stay and survival of patients (P-value 0.025).
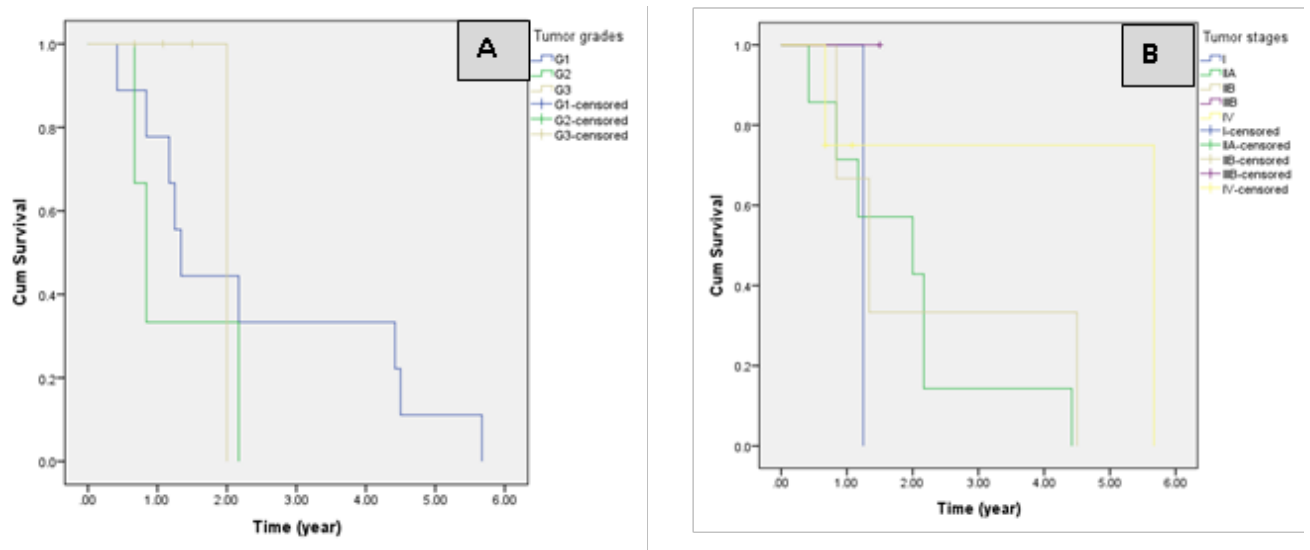

Figure 4: (A) Effect of tumor grade on survival, (B) Effect of tumor stage on survival.

\section{DISCUSSION}

The PNETs have a special biologic behavior that is different and less aggressive than that of the malignant pancreatic exocrine tumors, even in advanced metastatic stage [17-19]. Surgical treatment is the lone potentially curative chance and is associated with decreased risk of metastases and disease related mortality [20-22].The present study includes 16 case of malignant PNETs underwent curative resection. The curative resection, not only had been done for the primary malignant PNETs but also for metastatic liver lesions, either as simultaneous or as staged operation, as had been done before by other groups [23, 24].

In this study the ratio of non-functioningtumors is very high (93.7\%) when compared with other reported series that showed 75\%, 81\%, and 50\% [25-27]. The mean age at the time of diagnosis was 49.31 year, which is near to that reported in previous studies [25, 26, 28]. Different surgical procedures were performed in this study, with an overall complication rate of $43.7 \%$, which is higher than reported before [25, 26], the type of operative procedure was not found to be a factor on morbidity (P-value 0.0395 ), the male to female ratio is equal in this study unlike other reports that showed male predominance [26] or female predominance [28]. The majority of the tumors were located in the body of the pancreas which is differs to others which were located in the head and uncinate process [25] and in the tail of pancreas [26].

The 5- year overall survival rate is (82.2\%) and 5- year disease free survival is (75\%) which is near to survival in [26] and higher than the survival rate in [25]. Different clinical and pathological factors have been attributed to predict prognosis after curative resection for malignant PNETs [25]. The relation of tumor size and hepatic metastases with poor prognosis had been declared by some authors in patients with malignant gastrinomas [29], while others reported patients below 50 have better overall survival [23] and some discovered association of female gender with aggressive form of gastrinomas [30]. In the present study neither the tumor size, age of neither the patient nor the sex were independent factors on the prognosis in term of recurrence and survival. In our study the patients were recruited with malignant PNETs according to World Health Organization (WHO) classification, for whom potentially curative operation had been performed [31].

Among the patient's factors, only smoking, was assumed to be a risk factor for recurrence of the disease with a (P-value 0.029 ) but each of the sex, age and alcohol were not associated with disease recurrence. Tumor factors that exhibit no any effect on the disease recurrence were 
found to be tumor size, location, angio- invasion and gross invasion to other viscera as type of operation that is performed and postoperative chemotherapy.

This study revealed significant association between the disease recurrence with tumor grade (Pvalue 0.027 ), lymph node involvement (P-value 0.027 ) and tumor stage (P-value 0.017 ), which is near to the results achieved by other authors [32, 33].

Among patient's variables that impact on survival jaundice alone as a presenting symptom left significant effect on survival with a (P-value 0.018 ) with the rest of the patients factors have no significant role on survival. Among the tumor's variables each of the tumor grade (P-value 0.001), lymph node metastasis (P-value 0.001), invasion of other organs (P-value 0.018) and recurrent disease (P-value 0.001 ) have significant impact on survival similar to that association reported in $[25,26]$, except for the stage of tumor with a (P-value 0.51$)$ which is differs to that of [26].

\section{CONCLUSION}

In conclusion, pancreatic NETs have favorable long- term survival after surgical resection even in the presence of liver metastases depending on the grade of differentiation of tumor and lymph node metastases rather than the liver metastases and other factors. Pancreatic neuroendocrine tumors should be suspected and better to be excluded, if possible, in every pancreatic lesion with liver metastases.

\section{REFERENCE}

[1] J. C. Yao, M. Hassan, A. Phan, C. Dagohoy, C. Leary, J. E. Mares, et al., "One hundred years after"carcinoid":epidemiology of and prognostic factors for neuroendocrine tumors in 35,825 cases in the United States," Journal of clinical oncology, vol. 26, pp. 3063-3072, 2008.

[2] H. Dai, X. Hong, X. Wang, C. Lin, W. Wu, and Y. Zhao, "Pancreatic neuroendocrine tumor cancer stem cells: potential novel therapeutic targets?," Translational Cancer Research, vol. 5, pp. 860-870, 2016.

[3] F. Ehehalt, H. D. Saeger, C. M. Schmidt, and R. Grützmann, "Neuroendocrine tumors of the pancreas," The oncologist, vol. 14, pp. 456-467, 2009.

[4] J. Franko, W. Feng, L. Yip, E. Genovese, and A. J. Moser, "Non-functional neuroendocrine carcinoma of the pancreas:incidence, tumor biology, and outcomes in 2,158 patients,"Journal of Gastrointestinal Surgery, vol. 14, pp. 541-548, 2010.

[5] T. R. Halfdanarson, K. Rabe, J. Rubin, and G. M. Petersen, "Pancreatic neuroendocrine tumors (PNETs): incidence, prognosis and recent trend toward improved survival," Annals of oncology, vol. 19, pp. 1727-1733, 2008.

[6] M. Modlin, K. Oberg, D. C. Chung, R. T. Jensen, W. W. de Herder, R. V. Thakker, et al., "Gastroenteropancreatic neuroendocrine tumours," The lancet oncology, vol. 9, pp. 61-72, 2008.

[7] R. S. Chamberlain, D. Canes, K. T. Brown, L. Saltz, W. Jarnagin, Y. Fong, et al., "Hepatic neuroendocrine metastases:does intervention alter outcomes?,"Journal of the American College of Surgeons, vol. 190, pp. 432445, 2000

[8] M. Modlin, K. D. Lye, and M. Kidd, "A 5-decade analysis of 13,715 carcinoid tumors," Cancer: Interdisciplinary International Journal of the American Cancer Society, vol. 97, pp. 934-959, 2003.

[9] K. Öberg and B. Eriksson, "Endocrine tumours of the pancreas," Best practice \& research Clinical gastroenterology, vol. 19, pp. 753-781, 2005.

[10] G. Klöppel, A. Perren, and P. U. Heitz, "The gastroenteropancreatic neuroendocrine cell system and its tumors: the WHO classification," Annals of the New York academy of sciences, vol. 1014, pp. 13-27, 2004.

[11] D. C. Metz and R. T. Jensen, "Gastrointestinal neuroendocrine tumors:pancreatic endocrine tumors," Gastroenterology, vol. 135, pp. 1469-1492, 2008.

[12] J. C. Yao, M. P. Eisner, C. Leary, C. Dagohoy, A. Phan, A. Rashid, et al., "Population-based study of islet cell carcinoma," Annals of surgical oncology, vol. 14, pp. 3492-3500, 2007.

[13] J. Sun, "Pancreatic neuroendocrine tumors," Intractable \& rare diseases research, vol. 6, pp. 21-28, 2017.

[14] M. H. Kulke, M. H. Shah, A. B. Benson, E. Bergsland, J. D. Berlin, L. S. Blaszkowsky, et al., "Neuroendocrine tumors, version 1.2015," Journal of the National Comprehensive Cancer Network, vol. 13, pp. 78-108, 2015.

[15] H. Nave, E. Mössinger, H. Feist, H. Lang, and H.-R. Raab, "Surgery as primary treatment in patients with liver metastases from carcinoid tumors: a retrospective, unicentric study over 13 years," Surgery, vol. 129, pp. 170175, 2001.

[16] G. Capurso, R. Bettini, M. Rinzivillo, L. Boninsegna, G. Delle Fave, and M. Falconi, "Role of resection of the primary pancreatic neuroendocrine tumour only in patients with unresectable metastatic liver disease: a systematic review," Neuroendocrinology, vol. 93, pp. 223-229, 2011.

[17] E. Dixon and J. L. Pasieka, "Functioningand nonfunctioning neuroendocrine tumors of the pancreas," Current 
opinion in oncology, vol. 19, pp. 30-35, 2007.

[18] S. N. Hochwald, S. Zee, K. C. Conlon, R. Colleoni, O. Louie, M. F. Brennan, et al., "Prognostic factors in pancreatic endocrine neoplasms: an analysis of 136 cases with a proposal for low-grade andintermediate-grade groups,"Journal of Clinical Oncology, vol. 20, pp. 2633-2642, 2002.

[19] H. L. O'Grady and K. C. Conlon, "Pancreatic neuroendocrine tumours," Eur J Surg Oncol, vol. 34, pp. 324-32, Mar 2008.

[20] M. Lombardi, N. De Lio, N. Funel, C. Sardella, D. Russo, C. Urbani, et al., "Prognostic factors for pancreatic neuroendocrine neoplasms (pNET) and the risk of small non-functioning pNET," Journal of endocrinological investigation, vol. 38, pp. 605-613, 2015.

[21] J. S. Hill, J. T. McPhee, T. P. McDade, Z. Zhou, M. E. Sullivan, G. F. Whalen, et al., "Pancreatic neuroendocrine tumors:the impact of surgical resection on survival," Cancer: Interdisciplinary International Journal of the American Cancer Society, vol. 115, pp. 741-751, 2009.

[22] R. Doi, "Determinants of surgical resection for pancreatic neuroendocrine tumors," Journal of Hepato-BiliaryPancreatic Sciences, vol. 22, pp. 610-617, 2015.

[23] V. Fendrich, P. Langer, I. Celik, D. K. Bartsch, A. Zielke, A. Ramaswamy, et al., "An aggressive surgical approach leads to long-term survival in patients with pancreatic endocrine tumors," Annals of surgery, vol. 244, p. 845, 2006.

[24] J. M. Sarmiento, F. G. Que, C. S. Grant, G. B. Thompson, M. B. Farnell, and D. M. Nagorney, "Concurrent resections of pancreatic islet cell cancers with synchronous hepatic metastases: outcomesof an aggressive approach," Surgery, vol. 132, pp. 976-983, 2002.

[25] G. K. Bonney, D. Gomez, S. H. Rahman, C. S. Verbeke, K. R. Prasad, G. J. Toogood, et al., "Results following surgical resection for malignant pancreatic neuroendocrine tumours. A single institutional experience," JOP, vol. 9, pp. 19-25, 2008

[26] M. S. Janot, S. Kersting, T. Herzog, A. M. Chromik, and W. Uhl, "Prognosis and long-term survival after operation in patients with pancreatic and peripancreatic neuroendocrine tumors of a single center," JOURNAL OF THE PANCREAS, vol. 17, pp. 182-188, 2016

[27] T. Ito, H. Sasano, M. Tanaka, R. Y. Osamura, I. Sasaki, W. Kimura, et al., "Epidemiological study of gastroenteropancreatic neuroendocrine tumors in Japan," Journal of gastroenterology, vol. 45, pp. 234-243, 2010.

[28] P. Tomassetti, D. Campana, L. Piscitelli, R. Casadei, D. Santini, F. Nori, et al., "Endocrine pancreatic tumors:factors correlated with survival,"Annals of Oncology, vol. 16, pp. 1806-1810, 2005.

[29] F. Yu, D. J. Venzon, J. Serrano, S. U. Goebel, J. L. Doppman, F. Gibril, et al., "Prospective study of the clinical course, prognostic factors, causes of death, and survival in patients with long-standing Zollinger-Ellison syndrome," Journal of Clinical Oncology, vol. 17, pp. 615-615, 1999.

[30] J. A. Norton and R. T. Jensen, "Resolved and unresolved controversies in the surgical management of patients with Zollinger-Ellison syndrome," Annals of surgery, vol. 240, p. 757, 2004.

[31] R. Kanthan, J.-L. Senger, S. Ahmed, and S. C. Kanthan, "Pancreatic Neuroendocrine Tumors in the 21st Century-An Update," Journal of Cancer Therapy, vol. 8, p. 1194, 2017.

[32] B. Zhou, J. Duan, S. Yan, J. Zhou, and S. Zheng, "Prognostic factors of long-term outcome in surgically resectable pancreatic neuroendocrine tumors: A 12-year experience from a single center," Oncology letters, vol. 13, pp. 1157-1164, 2017.

[33] H. Yamaguchi, Y. Kimura, M. Imamura, M. Nagayama, T. Ito, T. Nobuoka, et al., "Oncological Features and Outcomes of Curatively Resected Non-Functional Pancreatic Neuroendocrine Tumor: Single Institute Experiences," JOP. J Pancreas (Online), vol. 18, pp. 380-386, 2017. 